\title{
DIRECTIONS TO MODERNIZE TEACHING METHODOLOGY Nicolae CĂPĂȚîNĂ
}

\author{
“Nicolae Balcescu” Land Forces Academy, Sibiu, Romania
}

\begin{abstract}
Article presents the main directions of modernization of teaching methods, factor for modernization of education. Modernization of teaching methods is required by changes taking place in society today latter directly influencing the conduct of education.

Shift from teacher-centered education to student-centered learning and changing paradigms instructional, teaching methods require modernization and transformation of his conception of education.

Classical paradigm of teaching and learning profound changes, transforming the teaching learning, resulting in the need to change teacher.
\end{abstract}

\section{Keywords: teaching methods, education, critical thinking, teacher}

\section{Conceptual insights}

A method is not good or bad in itself, but by relating them to a teaching situation can be appreciated, valued due to the use or suitability in terms of adequacy and efficiency.

Modernising education involves methodological innovations, along with restructuring in the finalities. The main directions of development of teaching methodology include:

$\checkmark$ promoting active-participatory methods;

$\checkmark$ deepening formative methods;

$\checkmark$ recovery of traditional methods of activation towards participants;

$\checkmark$ extension methods based on practical action;

$\checkmark$ deepening of heuristic methods;

$\checkmark$ opening methodology to the requirements of lifelong learning;

$\checkmark$ combination with the methods of individual learning cooperative learning;

Improving methods to be made emphasizing the heuristic character, and creativity. A trend that can be observed today is the introduction and application of methods of teaching initially used in other areas: problem solving, discovery, algorithmic modeling, structural analysis, computerization, computer training, etc. Modernization of teaching methods is required by changes taking place in today's society and influencing education: increasing the role of science, the accelerating pace of change, the increasing demand for education, facts which were not provided by traditional methodology, it sometimes becomes insufficient and ineffective.

\section{Critical thinking essential factor in} modernizing teaching methods

In the modernization of teaching methods is absolutely necessary to bring into question the methods of developing critical thinking. Daniela Cretu (1999) stated that critical thinking was wrong often considering a "discipline" of study or set of skills to be learned, memorized and then applied.

Critical thinking in reality is a product that reaches our thinking when we think critically of habit, as natural way of interacting with ideas and information that we receive or we discover. 
At the same time, it is a process that occurs when the learner puts questions like: "What significance have this information for me?", "How can I use this information?", "How can I link these knowledge I knew beforehand what? ", "What could be the consequences of these ideas, for me and for others?", "What do I think about this?",

"What can I do otherwise now that have this information? ", "How my beliefs are affected by these ideas?".

Teaching and learning methods using critical thinking is not a simple task, nor one that is done in a particular lesson and then looked.

\section{Conditions and directions for promoting critical thinking}

There are a number of conditions that must be met by each teaching activities which are essential for the promotion of critical thinking[1]:

$\checkmark$ you have found time and create conditions for the experiences of thought;

$\checkmark$ participants must leave to speculate;

$\checkmark$ you must accept the diversity of ideas and opinions;

$\checkmark \quad$ should be promoted actively involving students in learning;

$\checkmark$ participants should not feel that risk being ridiculed if their ideas, their views are not shared by others;

$\checkmark$ you have shown confidence in the ability of each person to think critically.

To get to think critically, students must:

$\checkmark$ to develop self-confidence and understand the value of their ideas and opinions;

$\checkmark \quad$ to be actively involved in the learning process;

$\checkmark$ to listen respectfully disagree;

$\checkmark$ be prepared to formulate, argue and remove judgments.

\section{Stages of critical thinking}

A didactic approach based on methods of critical thinking through three stages: evocation, realization of meaning and reflection, in each of these stages being used various combinations of methods.
Invoking involves establishing a starting point in teaching a new content by probing previous experience of participants, the experience to be realized to date.

Making direction is the second stage, to monitor the understanding of the new content, maintaining the involvement of interest set in the previous step.

Reflection is the concluding phase in which the approach and actually acquiring new knowledge, understanding sustainable applying similar information to solve complex situations.

Thus guiding learning, teachers are more than sources of information to be stored. They are authentic learning facilitators of knowledge that students can apply in the future.

The teacher's role is to partner involved in the learning process, a process in which participants contribute with the mind and personality traits and energy they have, so to make personal changes required for sustainable knowledge acquisition.

A trend of modernization of education comes conception and instructional paradigms change, the evolution of institutionalism to knowledge, education transition from teacher-centered to studentcentered education.

\section{Objectives and directions education}

Faced with the new structure of human social needs, education must redefine its goals and provide a new direction of education: training before the passage of information, training and capacity building intellectual shift-acting and mental processes of students by the teacher prior to transmitting information, without denying the importance of the latter.

Student-centered methodology is a methodology differentiating, individualization and personalization of the learning process, providing equal opportunities for all.

Classical teaching-learning paradigm change radically transforming teaching learning, resulting in the need to change teacher. 
Thus, we can formulate a series of recommendations for teachers, both those engaged in classical education and for those who lead modern learning activities even remotely deployed involving information and communication technology [2]:

$\checkmark$ adapt lessons in front and in electronic format based on experiences and interests of students, to fit better with what they want to learn;

$\checkmark \quad$ to use information provided directly or knowledge in electronic form as a guide, not an absolute rule;

$\checkmark \quad$ to focus discussion or brainstorming on participants' prior knowledge and experience;

$\checkmark \quad$ to encourage students to have an open attitude towards science and learning, to stimulate interest in acting as a facilitator in understanding, not explaining the position of a superior;

$\checkmark$ to use scientific models as often as possible;

$\checkmark$ to allow time for reflection; students must have time to reflect on new ideas and solve conflicts arising when concepts or do not correspond to the reference scheme;

$\checkmark$ to accept that silence during a discussion is not a bad thing

$\checkmark$ provide opportunities for participants to discuss among themselves;

$\checkmark$ to ask open questions and contradictions reveal to stimulate investigation;

$\checkmark$ provide less time teaching activity, but instead more group activity;

$\checkmark \quad$ to teach students to be aware of their thoughts and actions, so as not to feel uncomfortable in the presence of what is not yet known.

Student activism is understood as an action and self-training, personality development by stimulating the activity of participants and methodical guidance. Activation requires implementation of a suite of actions:

$\checkmark \quad$ the awakening and growing interest in knowledge, mental performance of the personal effort; exercise capacity to acquire knowledge, skills training orientation issues raised autonomous practice;

cultivation investigative spirit;

Constructivist learning environments in providing construction knowledge and context dependence of providing multiple representations of reality, assuming the existence of authentic learning tasks in meaningful contexts.

It also provides learning environments such case studies or real situations and encourages reflection on activities that were conducted, the results of the experience.

In a growing interest in so-called activeparticipative methods, activism driven by internal motives, the student's own initiative curiosity to know the intrinsic desire to observe and explain, investigate and build, explore and discover, invent and create.

What is very important for activeparticipative methods is precisely their ability to stimulate active participation and full physical and mental, individual and collective of students in the learning process.

These methods focus on process knowledge (learning) and not knowledge products. The active-participative methods have a strong educational and training aiming intellectual, logical-mathematical development of operations, development of learning motivation etc.

6. Guidelines and requirements for teaching sustained effort

Of course, in one way or another, each method offers countless possibilities for engagement of learners, but the degree of activation differs from one method to another.

Real possibilities of involving the participants in the teaching process depend on respect for activating the demands of students:

$\checkmark$ psychological preparation for learning (providing motivation for learning, awareness, orientation, attention to material studied, familiarity with the material, creating and maintaining a 
climate of trust, a stimulating working atmosphere);

$\checkmark$ identifying sources of distortion and prevent them (it is the interference caused by faulty organization and development of teaching and learning, noise generated by the surrounding environment, the fatigue or inattention to students or teachers from incompatible psychological disturbances )

$\checkmark$ organize and conduct rational learning (including as many analyzers in the process of collecting information, creating optimal outbreaks in the cerebral cortex excitability, development and practice of inhibition of differentiation, permanent joint language with intuitive media);

$\checkmark$ using active-participative methods (methods that determine the student to search, investigate, only to find the content you are going to acquire, process knowledge, to reorganize, to systematize, to work independently, to work with his colleagues, to exchange views, impressions, to make direct contact with real life situations, with practical problems, etc.).

\section{Conclusions}

I believe that interactive teaching strategies (teaching-learning-assessment) is a priority for transforming teaching methodology that provides clear benefits of a learning organization pedagogical reasons, easy and fun at the same time a strong activeparticipatory the students with opportunities for cooperation and effective communication.

Learning objectives must be consistent with the type of interaction designed for that lesson: between student-student and / or group of students (horizontal) between teacher and student or group of students (vertical) and between student - content in of educational processes.

Systematic use of strategies of interaction between participants in the activity involves conducting effective communication and constructive relations in which all those who take part in discussions to benefit plans cognitive, affective-motivational, attitudinal, social and practical use.

It is a reciprocal action of influence, social and emotional in groups as interactive strategies group develops a dynamic relationship, communication and exchange of information between individuals, dependent relationship influences, behaviors, socio-cognitive conflict developed and group cohesion.

To achieve educational outcomes and increase benefits in terms of personality education, but cannot neglect that requires a combination of individual activities with those of groups/microgroup and support cooperative learning, learning related to constructive competition, individual and intra / intergroup.

\section{References}

[1] Cretu Daniela, Psycho. Elements of teacher training, Sibiu, Imago Publishing, 1999

[2] Cerghit Ioan, Alternative and complementary training systems. Structures, Styles, Strategies, Bucharest, Aramis, 2002

\section{Bibliography}

Albulescu M., Teaching Humanities disciplines, Bucharest, Polirom, 2001.

Ausubel, D., Floyd, R., Learning in school, Bucharest, Didactic and Pedagogic, 1981.

Bocoş M., Interactive Learning. Highlights for reflection and action, Cluj- Napoca, Cluj University Press, 2002.

Bruner. JS, The intellectual education, Scientific Publishing, 1970.

Cerghit I., Alternative and complementary training systems. Structures, Styles, Strategies, Bucharest, Aramis, 2002.

Cerghit I., Educational methods, Bucharest,Polirom, 2006. 
Cojocariu V.M., Theory and methodology of training, Polirom, Bucharest, 2002.

Cretu D., Nicu . A., Mara. D., Pedagogy. Initial teacher, Sibiu, University "Lucian Blaga", 2005.

Cucoş Constantin, Education, Bucharest, Polirom, 2007.

Cucoş Constantine (ed.), Psycho finalized exam and teaching degrees, Iasi, Polirom, 1998.

Diaconu.M., Jinga Ioan., Education, Bucharest, Academy of Economic Studies, 2004.

Dumitru Cristea, Social psychology, Publisher Pro Transylvania. 